\title{
Pendidikan Kewargaan untuk Demokrasi di Indonesia
}

\author{
AzyumardiAzra
}

"All societies have a continuing interest in the way their young people are prepared for citizenship and learn to take part in public affairs. [Since] the 1990s, this has become a matter of increased importance not only in societies striving to establish or re-establish democratic governments, but also in societies with continous and long-established democratic traditions. What effective citizenship means and the role of formal education in building a civic culture is important not only to govemments and policy-makers, but also to the public at large" (Torney-Purta, Schwille \& Amedeo, 1999:12). "There is an old saying that the course of civilization is a race between catastrophe and education. In a democracy such as ours, we must make sure that education wins the race" (John F. Kennedy, 1958, dalam Print et all, 1999:9).

Kata kunci: pendidikan kewargaan, demokrasi dan kultur keadaban

D endidikan kewargaan jelas mulai mendapatkan momentumnya di Indonesia. Meski wacana publik_apakah dalam media massa maupun pembahasan seminar dan lokakarya - tentang subyek ini masih sangat terbatas, tetapi sulit diingkari bahwa urgensi pendidikan kewargaan mulai disadari semakin banyak pihak; dan berbagai "eksperimen" baik pada tingkat konsep maupun praksis tengah dirumuskan dan diujicobakan.

'Selanjutnya, pada tingkat praksis, IAIN Syarff Hidayatullah Jakarta tahun akademis 2000 mulai menyelenggarakan "pilot project" pendidikan kewargaan untuk "menggantikan" MKDU Pancasila, dan Kewiraan. Proyek percontohan ini telah menghasilkan sebuah buku teks, Pendidikan Kewargaan (Civic Education): Demokrasi, HAM \& Masyarakat Madani (2000). Proyek percontohan pertama di Indonesia untuk tingkat pendidikan tinggi ini-dengan bantuan dana dari The Asia Foundationmenurut evaluasi cukup berhasil dan menjanjikan untuk menaburkan civic culture di kalangan mahasiswa.

\section{"Point of No Return"}

Perkembangan Indonesia menuju demokrasi dalam tiga tahun terakhir ini agaknya tidak mungkin lagi dimundurkan (point of no return). Perubahan Indonesia menuju demokrasi jelas sangat dramatis; dan Indonesia mulai disebut-sebut sebagai salah satu negara demokrasj terbesar. Perubahan Indonesia menuju demokrasi tidak bisa lain mengikuti kecenderungan pertumbuhan dramatis demokrasi pada tingkat internasional secara keseluruhan. Indonesia pada akhirnya mengikuti apa yang disebut banyak ahli sebagai "third wave of democracy". Menurut berbagai kajian, jumlah negara yang secara formal menganut demokrasi meningkat drastis pada 
dasawarsa 1990an; jumlah meningkat dari 76 negara (46.1 persen) dari jumlah seluruh negara di dunia menjadi 117 (63.1 persen). Tetapi di samping perkembangan yang menggembirakan ini, kekhawatiran juga mulai berkembang melihat kecenderungan mandeknya demokrasi, atau ketidakpastian transisi menuju demokrasi, seperti terjadi di Eropa Timur, Balkan, dan kini juga di Indonesia.

Banyak perkembangan terjadi di Indonesia sejak jatuhnya Presiden Soeharto pada 20 Mei 1998 dari kekuasaan yang dipegangnya selama lebih tiga dasawarsa menuju ke arah pengembangan demokrasi. Penggantinya, Presiden BJ Habibie dalam interregnum-nya memperkuat momentum transisi Indonesia menuju demokrasi melalui berbagai kebijakannya sejak dari penerapan sistem multi partai, Pemilu 1999 yang dinilai paling demokratis sejak Indonesia merdeka, sampai kepada kebebasan pers, dan meningkatnya fungsi check and balances DPR.

Tetapi, pada saat yang.sama harus diakui, pertumbuhan demokrasi atau transisi Indonesia secara damai menuju demokrasi, juga menimbulkan banyak kegamangan dan kecemasan. Pernilihan Abdurrahman Wahid sebagai presiden keempat Indonesia dalam Sidang Umum MPR Oktober 1999 memang sempat menumbuhkan harapan bagi percepatan transisi Indonesia secara damai menuju demokrasi. Tetapi, berkaitan erat dengan masalah-masalah Presiden Wahid sendiri baik secara personal maupun dalam hubungannya dengan kekuatan-kekuatan politik lain, orang kini semakin cemas dengan perjalanan Indonesia menuju demokrasi yang genuine dan otentik. Jika demokrasi adalah peaceful resolution of conflict, orang menyaksikan semakin meningkatnya kecenderungan penyelesaian konflik melalui cara-cara tidak demokratis, seperti penggunaan mob politics, money politics, dan cara-cara undemocratic lainnya.

Meningkatnya kecenderungan penggunaan cara-cara tidak demokratis dan kekerasan dalam politik Indonesia belakangan ini, sebagian besarnya bersumber dari konflik di antara elit politik yang tidak kunjung terselesaikan sampai saat ini. Jika salah satu esensi demokrasi dan politik adalah "art of compromise" dan respek terhadap perbedaan sikap politik, orang justru menyaksikan kian meningkatnya sikap pokoke pada kalangan elit politik dan massa. Lebih celaka lagi, sikapsikap seperti itu kemudian diberi legitimasi keagamaan dan teologis oleh kalangan ulama, sehingga potensi kekerasan yang mengancam demokrasi semakin menguat lagi.

Agaknya benar, masyarakat Indonesia umumnya - termasuk elit politik yang mengklaim sebagai "pejuang demokrasi"memiliki hanya sedikit pengalaman demokrasi yang benar-benar otentik. Kalaupun Indonesia dulu pemah menerapkan "Demokrasi Terpimpin" di masa Presiden Soekarno, dan "Demokrasi Pancasila" pada masa Presiden Soeharto, maka pada praktiknya, semua jtu agaknya tidak lebih daripada sekadar "pseudo-demokras" atau "quasi-demokrasi".

Mengalami demokrasi (experiencing democracy), dengan demikian, merupakan sesuatu yang baru bagi masyarakat Indonesia umumnya. Karena itu, mengalami demokrasi, kalau perlu akan melibatkan proses "trial and enror" seperti sering diulangulang Nurcholish Madjid. Pada batas tertentu, argumen Nurcholish Madjid tentang "trial and error" demokrasi bisa dipahami. Namun, pada segi lain, pandangan itu dapat 
secara implisit merupakan justifikasi yang tidak pas bagi kecenderungan-kecenderungan yang tidak kondusit dan tidak sesuai dengan kerangka pertumbuhan demokrasi. Lebih berbahaya lagi, "trial and error" demokrasi dapat memunculkan ongkosongkos sosial, politik dan ekonomi yang sangat mahal bagi negara-bangsa Indonesia.

Oleh sebab itu, pertumbuhan demokrasi di Indonesia seyogyanya tidak diperlakukan secara "trial and error". Pertumbuhan demokrasi juga tidak bisa diperlakukan secara taken for granted, membiarkannya berkembang apa adanya lewat trial and error. Sebaliknya, demokrasi tidak hanya perlu diperjuangkan, tetapi lebih dari itu harus disemaikan, ditanamkan, dipupuk dan dibesarkan melalui upayaupaya terencana, teratur, dan terarah pada seluruh lapisan masyarakat. Jika tidak, sangat boleh jadi "pohon demokrasi" yang mulai tumbuh sekarang ini akan layu dan mati sebelum sempat berurat berakar.

\section{Pendidikan Demokrasi dan Kewargaan}

Sebagaimana diakui semakin banyak pakar tentang demokrasi pada level internasional, cara paling strategis untuk "mengalami" demokrasi adalah melalui apa yang disebut sebagai "democracy education". Pendidikan demokrasi singkatnya secara substantif menyangkut sosialisasi, diseminasi dan aktualisasi konsep, sistem, nilai, budaya dan praktek demokrasi melalui pendidikan.

Pendidikan demokrasi tidak hanya urgen bagi negara-negara yang sedang berada dalam transisi menuju demokrasi seperti Indonesia, tetapi juga bagi negaranegara yang telah mapan demokrasinya. Kenyataan inilah yang terlihat misalnya dari pembentukan "Civitas International" pada Juni 1995 di Praha. Dihadiri tidak kurang dari 450 pemuka pendidikan demokrasi dari 52 negara, para peserta sepakat membentuk "Civitas International" yang menyimpulkan pentingnya pendidikan demokrasi bagi penumbuhan "civic culture" untuk keberhasilan pengembangan dan pemeliharaan pemerintahan demokratis (democratic govemance).

Penumbuhan dan pengembangan civic culture dapat dikatakan merupakan salah satu tujuan penting pendidikan kewargaan (civic education). Tetapi harus segera diakui, sementara para ahli pendidikan kewargaan umumnya sepakat bahwa peranan pendidikan kewargaan dalam pengembangan demokrasi dan kewargaan demokratis telah jelas, tetapi dalam prakteknya masih terdapat perbedaanperbedaan. Mereka sepakat, bahwa demokrasi-demokrasi yang tengah tumbuh-seperti Indonesia sekarangmiemerlukan sarana di mana generasi muda umumnya dapat menjadi tahu dan sadar tentang pengetahuan, keahlian, ketrampilan dan nilai-nilai yang diperlukan untuk menyangga, memelihara dan melestarikan demokrasi. Tetapi, seperti dikemukakan Print, bagaimana semua hal itu bisa dicapai melalui pendidikan kewargaan tidaklah begitu jelas (Print 1999:11).

Harus diakui, pendidikan kewargaan yang semakin menemukan momentum pada 1990an dipahami secara berbedabeda. Bagi sebagian ahli, pendidikan kewargaan diidentikkan dengan "pendidikan demokrasi" (democracy education). Di sini pendidikan kewargaan mencakup kajian dan pembahasan tentang pemerintahan, konstitusi, lembaga-lembaga demokrasi, rule of law, dan hak dan kewajiban warganegara. Sementara bagi sebagian ahii 
lain, pendidikan kewargaan disebut citizenship education yang muatannya memberikan penekanan pada proses-proses demokrasi, partisipasi aktif dan keterlibatan warganegara dalam masyarakat madani.

Masih ada lagi sebagian ahli yang berpendapat pendidikan kewargaan mencakup pengetahuan tentang lembagalembaga dan sistem yang terdapat dalam pernerintahan, warisan politik, proses-proses demokrasi, hak dan kewajiban warganegara, administrasi publik dan sistem hukum. Lebih jauh, pendidikan kewargaan juga mencakup keahlian dan pengetahuan tentang proses seperti kewarganegaraan aktif, refleksi kritis, penyelidikan dan kerjasama. Terakhir sekali, pendidikan kewargaan juga mencakup wilayah keadilan sosial, pengertian antarbudaya, dan kelestarian lingkungan hidup.

Dengan demikian, pendidikan demokrasi-yang dikemukakan di atasdalam segi-segi tertentu identik dengan "pendidikan kewargaan" (civic education). Tetapi, sebagaimana dijelaskan di atasterlihat bahwa pendidikan kewargaan lebih luas cakupannya daripada sekedar pendidikan demokrasi. Hal ini juga tercermin jelas dari rumusan Civitas International, bahwa pendidikan kewargaan yang efektif mencakup: Pertama, pemahaman dasar tentang cara kerja demokrasi dan lembagalembaganya. Kedua, pemahaman tentang "rule of law", dan HAM seperti tercermin dalam rumusan-rumusan, perjanjian dan kesepakatan internasional dan lokal. Ketiga, penguatan ketrampilan partisipatif yang akan memberdayakan peserta didik untuk meresponi dan memecahkan masalahmasalah masyarakat mereka secara demokratis. Keempat, pengembangan budaya demokrasi dan perdamaian pada lembaga-lembaga pendidikan dan seluruh aspek kehidupan masyarakat.
Pada beberapa negara Barat, seperti AS dan Australia, program pendidikan kewargaan telah menjadi bagian kurikulum sekolah setidak-tidaknya dalam satu dasawarsa terakhir. Negara-negara lain, seperti Inggris, baru mulai menerapkan pada tahun 2000 melalui program "citizenship education". Pada 2002 "citizenship education" akan menjadi matapelajaran wajib dalam kurikulum pendidikan dasar dan menengah lnggris.

Postulat yang berada di balikpenerapan pendidikan kewargaan di AS adalah bahwa pemeliharaan tradisi demokrasi tidak bisa diwariskan begitu saja; tetapi sebaliknya harus diajarkan, disosialisasikan, dan diaktualisasikan kepada generasi muda melalui sekolah. Lebih daripada postulat penting tersebut, dalam pandangan banyak ahli pendidikan dan demokrasi Barat, pendidikan kewargaan merupakan kebutuhan mendesak karena beberapa alasan kuat lainnya. Pertama, meningkatnya gejala dan kecenderungan politicaliliteracy, tidak melek politik di kalangan warganegara. Banyakwarga Barat, khususnya generasi muda tidak memiliki political literacy, tidak mengetahui persis cara kerja demokrasi dan lembagalembaganya. Kedua, meningkatnya political apathism, yang terlihat antara lain dari relatif sedikitnya jumlah warganegara yang memberikan suara dalam Pemilu, atau terlibat dalam proses-proses politik lainnya.

\section{Equivalensi Pendidikan Kewargaan}

Mempertimbangkan perkembangan "democracy education", "civic education", dan "citizenship education" yang relatif baru menemukan momentumnya di beberapa negara Barat, maka Indonesia sebenarnya sangat beruntung karena sudah berpenga- 
laman lama dalam bidang ini. Secara substantif, subyek ini sebagian besarnya telah tertampung dalam mata-pelajaran PPKn (Pendidikan Pancasila dan Kewarganegaraan) yang sejak 1994 berlaku mulai tingkat SD sampai SMU. Matapelajaran ini merupakan pengganti matapelajaran PMP (Pendidikan Moral Pancasila) yang diterapkan sejak 1975 sampai 1994. Sedangkan pada tingkat Perguruan Tinggi equivalensinya adalah matakuliah Pancasila, dan Kewiraan.

Kajian komparatif tentang "democracy educatior", "civic educatior" dan "citizenship education" pada sekitar 30 negara menunjukkan, hampir di seluruh negara ini tidak terdapat matapelajaran yang berdiri sendiri (independent subject/course) dalami bidang ini. Substansi pelajaran ini, sebaliknya tercakup dan terintegrasi ke dalam sejumlah mata-pelajaran, khususnya pada disiplin humaniora dan ilmu-ilmu sosial. Dengan kata lain, pendekatan yang diambilkan adalah "pendekatan integratif'.

Sekali lagi, dilihat dari segi ini, Indonesia dengan "separated approach" melàlui matapelajaran khusus PPKn; dan MKDU Pancasila, dan Kewiraan, sebenarnya telah berdiri di depan. Tetapi, harus diakui, terdapat sejumlah masalah dalam matapelajaran atau kedua MKDU tersebut. Akibatnya, mereka gagal dalam usaha sosialisasi dan diseminasi demokrasi, jangankan lagi untuk pembentukan cara berpikir (worldview) dan perilaku demokrasi di lingkungan peserta didik dan masyarakat sekolah/universitas umumnya.

Kegagalan jtu, hemat saya, bersumber setidaknya dari tiga hal. Pertama, secara. substantif, PPKn, Pancasila, dan Kewiraan tidak secara terencana dan terarah mencakup materi dan pembahasan yang lebih terfokus pada pendidikan demokrasi dan kewargaan. Materi-materi yang ada umumnya terpusat pada pembahasan yang bersifat idealistik, legalistik dan normatif. Kedua, kalaupun materi-materi yang ada pada dasarnya potensial bagi pendidikan demokrasi dan pendidikan kewargaaan, potensi itu tidak berkembang karena pendekatan dalam pembelajarannya bersifat indoktrinatif, regimentatif, monologis, dan tidak partisipatif.

Ketiga, ketiga subyek itu lebih teoritis daripada praktis. Akibatnya terdapat diskrepansi yang jelas di antara teori dan wacana yang dibahas dengan realitas sosialpolitik yang ada. Bahkan pada tingkat sekolah/universitas sekalipun diskrepansi itu sering terlihat pula dalam bentuk otoritarianisme bahkan feodalisme orangorang sekolah dan universitas itu sendiri. Akibatnya, bisa dipahami, kalau sekolah/ universitas gagal membawa peserta didik untuk "mengalami demokrasi".

\section{Penutup}

Upaya untuk menumbuhkan demokrasi di Indonesia melalui pendidikan kewargaan kelihatannya masih harus menempuh jalan panjang. Reorientasi subyek-subyek yang disebutkan, sekarang ini sedang menjadi pembahasan di kalangan para pendidik dan pengambil kebijakan di lingkungan Depdiknas. Jika sekolah/universitas akan memainkan peran penting dalam pembentukan demokrasi yang genuine dan otentik, sebaiknya dilakukan akselarasj dalam bidang ini.

Eksperimen reorientasi. MKDU Pancasila, dan Kewiraan pada tingkat perguruan tinggi, seperti saya singgung di atas, telah dimulai pada IAIN Syarif Hidayatullah Jakarta sejak tahun akademis 2000-2001 dengan memperkenalkan matakuliah "pendidikan kewargaan". 
Evaluasi dan assessment kritis setelah penerapan matakuliah "pendidikan kewargaan" menunjukkan, bahwa pengetahuan dan pemahaman mahasiswa tentang demokrasi, lembaga-lembaganya, dan praktiknya menjadi lebih baik. Karena itu, jika eksperimen ini bisa dikembangkan lebih luas, kita bisa berharap tumbuhnya civic culture, dan civility (keadaban) di lingkungan kampus, yang pada gilirannya akan menjadi kontribusi penting bagi pengembangan demokrasi yang genuine dan otentik pada negara-bangsa Indonesia secara keseluruhan. Wallahu a'lam bishshawabe

\section{Daftar Pustaka}

Audigier, Francois. 2000. Basic Concepts and Core Competencies for Education for Democratic Citizenship, Strasbourg: Council for Cultural CoOperation, Council of Europe.

Azra, Azyumardi. 2001 (forthcoming). "/slamic Perspective on the NationStatẽ: Political Islam in Post Soeharto Indonesia", in Virginia Hooker \& Amin Saikal (eds.), Islamic Perspective on the New Millennium, Canberra \& Singapore: The Australian National University (ANU) \& Institute of Southeast Asian Studies (ISEAS).

Azra, Azyumardi. 2001a. "Sustaining the Transition from Authoritarian Rule to Democracy: A Special Reference to Indonesia", makalah pada International Conference of International Council on Human Rights Policy (ICHRP) Jakarta: 16 Maret 2001.
Azra, Azyumardi. 2001b. "Pendidikan Kewargaan dan Demokrasi di Indonesia", Kompas, 14 Maret 2001.

Azra, Azyumardi. 2000. "Membangun Keadaban Demokratis: Ke Arah Budaya Politik Baru Indonesia", dalam Ninok Leksono (ed.), Indonesia Abad XX. Jakarta: Kompas.

Azra, Azyumardi. 1999. Menuju Masyarakat Madani: Gagasan, Fakta dan Tantangan. Bandung: Rosda Karya.

Birzea, Cesar. 2000. Education for Democratic Citizenship: A Lifelong Learning Perspective. Strasbourg: Council for Cultural Co-Operation, Council of Europe.

Carey, Liam \& Keith Forrester. 2000. Sites of Citizenship: Empowerment, Participation, and Partnerships. Strasbourg: Council for Cultural CoOperation, Council of Europe.

Duerr, Kartheinz et al. 2000. Strategies for Learning Democratic Citizenship. Strasbourg: Council for Cultural CoOperation, Council of Europe.

Hefner, Robert W. 2000. Civil Islam: Muslims and Democratization in Indonesia. Princeton: Princeton University Press.

Kerr, David. 1999. Citizenship Education: An International Comparison. [London]: NFER \& QCA.

McDonnell, Lorraine M, P. Michael Timpane \& Roger Benjamin (eds.). 2000. Re- 
discovering the Democratic Puposes of Education, Lawrence. Kansas: University of Kansas Press.

Print, Murray, James Ellickson-Brown \& Abdul Razak Baginda (eds.). 1999. Civic Education for Civil Society. London: ASEAN Academic Press.

Torney-Purta, John Schwille \& Jo-Ann Amadeo (eds.). 1999. Civic Education Across Countries: Twenty-Four National Case Studies from the IEA Civic Education Project, Delf: The Intemational Association for the Evaluation of Educational Achievement.
Taruna, JC Tukiman. 2001. "Wacana Pendidikan Kewargaan Abdurrahman Wahid (dalam Persandingan dengan "Revolusi Pendidikan" Tony Blair). Kompas 28 Februari 2001.

Ubaidillah, A. et al. 2000. Pendidikan Kewargaan (Civic Education): Demokrasi, HAM \& Masyarakat Madani. Jakarta: IAIN Jakarta Press.

Zamroni. 2001. Pendidikan untuk Demokrasi: Tantangan menuju Civil Society. Yogyakarta: Bigraf Publishing. 